\title{
COMPARISON OF BACTERIAL CORONAL LEAKAGE BETWEEN DIFFERENT OBTURATION MATERIALS (AN IN VITRO STUDY)

\author{
Mobarak $\mathrm{A}^{1} B D S$, Moussa $\mathrm{S}^{2} P h D$, Zaazou $\mathrm{A}^{3} P h D$, Abdelfattah $\mathrm{H}^{4} P h D$
}

\begin{abstract}
:
Introduction: Bacteria and their by-products are the main cause of pulpal and periapical diseases. That is why all routes between root canal system and peridontium should be sealed to prevent bacterial leakage.

Objectives: Was to compare the coronal bacterial leakage between different obturation materials.

Materials and methods: Sixty single-canaled lower premolars were used in this study. Teeth were decoronated to standardize root length to $12 \mathrm{~mm}$. Instrumentation was done using Protaper universal rotary system to file size F4, then teeth were divided into six groups, four experimental and two control $(n=10)$. Group I: obturation was done using CPoint and Endosequence bioceramic sealer using single-cone technique; Group II: obturation was done using Protaper gutta percha and Endosequence bioceramic sealer; Group III: obturation was done using Protaper gutta percha and Adseal resin sealer; Group IV: obturation was done using Protaper gutta percha and MTA Fillapex sealer; Group V: used as positive control; Group VI: used as negative control. Groups II, III, IV, VI were obturated using lateral condensation technique. A split-chamber microbial leakage model was used to detect bacterial leakage. Turbidity in the lower chamber was observed daily for 60 days. Data were analyzed using Kruskal-Wallis and Monte-Carlo test. Results: all experimental groups showed leakage throughout the study period, Group I showed the best results with a mean of (37.30 \pm 23.61) days while Group II and III showed nearly equal results with a mean of $(32.10 \pm 22.57)$ and (33.10 \pm 19.90$)$ days, respectively. Group IV showed a mean of $(16.90 \pm 8.21)$ days and was found to be statistically significant than the other groups $(\mathrm{P}=$ 0.048).

Conclusions: None of the tested materials were able to provide a complete hermetic seal. CPoint with endosequence bioceramic sealer provided the best coronal seal while MTA Fillapex was the worst. CPoint obturation system can be an alternative to lateral condensation technique.

Keywords: Endodontics, Bacterial leakage, CPoint, Endosequence bioceramic sealer, Adseal, MTA Fillapex.

1- Instructor at the Conservative Dentistry Department, Faculty of Dentistry, Alexandria University, Alexandria, Egypt.

2- $\quad$ Professor of Endodontics, Faculty of Dentistry, Alexandria University, Alexandria, Egypt.

3- Assistant Professor of Endodontics, Faculty of Dentistry, Alexandria University, Alexandria, Egypt.

4- Professor of Microbiology, Head of Microbiology department, High Institute of Public Health, Alexandria University, Egypt.
\end{abstract}

\section{INTRODUCTION}

Complete obturation and hermetic seal of the root canal system is a critical step in successful root canal therapy, providing a bacterial-tight seal to inhibit bacterial penetration and their by-products into the cleaned and disinfected root canal system. For this reason, different endodontic materials and obturation techniques have been developed for decreasing microleakage and improvement of the seal of the prepared root canals.

The most common obturation technique is the cold lateral condensation of gutta percha using different type of sealers. The sealer is very important for long-term seal of the root canal filling because it adheres gutta percha to the root canal dentin and fills irregularities and spaces among gutta percha cones and between the root canal walls and fillings (1).

Endosequence BC sealer (Brasseler USA, Savannah, GA) is a new bioceramic sealer used with gutta percha. Endosequence BC Sealer is a premixed and injectable endodontic sealer, and its nanoparticle size allowed it to flow into canal irregularities and dentinal tubules. It is hydrophilic and uses moisture in dentinal tubules to initiate and complete its setting reaction. In addition, no shrinkage occurs on setting, resulting in a gap-free interface between the gutta-percha, sealer, and dentin (2). BC sealer has the ability to form hydroxyapatite forming chemical bond with the dentin wall (3). It is composed of calcium silicates, calcium phosphate monobasic, calcium hydroxide and zirconium oxide.

MTA Fillapex (Angelus, PR, Brasil) is a MTAbased sealer. Its composition after mixing is basically MTA, salicylate cement, natural resin, bismuth and silica (4). MTA Fillapex is the first two paste MTA-based root canal sealer. According to the manufacturers its MTAbased composition provides a perfect sealing integrity and high biological regeneration (5).

Adseal sealer (Meta Biomed Co, Korea) is a resinbased sealer. It contains epoxy resin, zirconium oxide, Ethylene glycol salycilate, and bismuth subcarbonate. Available in two paste-containing tubes (6), it has good adaptation to canal walls, low solubility, good flow and good radiopacity (7). 
CPoint obturation system (EndoTechnologies, Shrewsbury, USA), also known as Propoint which is a part of the Smartseal obturation system (8) is a novel single-cone hydrophilic system, according to the manufacturer, which provides a three-dimensional seal as it had greater efficiency in filling simulated lateral canals and a comparable homogeneity of obturation (9). CPoint cones contain a central polyamide core to provide good handling with an outer bonded hydrophilic polymer coating, which expands laterally without expanding axially by absorbing residual water from the instrumented root canal space and the naturally present moisture in the dentinal tubules (8). The lateral expansion of CPoints is claimed to occur nonuniformly with the expandability depending on the extent to which the hydrophilic polymer is pre-stressed (i.e., contact with a canal wall will reduce the rate or extent of polymer expansion) (10).

The sealing ability is a basic feature that needs to be tested for every root canal filling material or technique. Many experimental tests have been developed to detect the leakage that occurs along root fillings. Despite the limitation of the in vitro leakage tests, they supply an appropriate initial framework of new filling materials and techniques $(11,12)$. These methods include dye penetration, glucose leakage, fluid transport, electrochemical, radioisotopes and bacterial leakage. The bacterial leakage model was used in this study as it is more clinically relevant, producing more precise and reproducible data (13), using the etiologic agent of apical periodontitis (14).

The aim of the present in vitro study was to compare the coronal bacterial leakage through different obturation material and to study the effectiveness of the single-cone CPoint system to resist bacterial leakage compared to that of laterally condensed gutta percha with different sealers.

\section{MATERIALS AND METHODS}

Sixty single-canaled lower premolar teeth with fully developed root apices were used in this study. Teeth were thoroughly cleaned from any soft tissue or calculus deposition using curettes, with care not to damage the root surface.

To ensure the same length for all specimens, the crowns of all teeth were removed using diamond disks keeping the length of all roots standardized at $12 \mathrm{~mm}$. Apical patency was checked using \#10 K-files. \#15 Kfile was inserted into each root canal for determination of the working length.

Instrumentation was done in a crown-down technique using rotary Protaper universal system (Dentsply Maillefer SA, Baillaigues, Switzerland). Rotary instrumentation was performed with the aid of electrical motor X-Smart device at speed of 250 RPM and torque of $3 \mathrm{~N}$. The sequence of files used during instrumentation was that recommended by the manufacturer as SX, S1, S2, F1, F2, F3 and F4 was used as final apical file. Shaping files were used in brushing motion while finishing files was used in straight in and out motion. Glyde file prep was placed on each file before insertion inside the canals. Smear layer removal was done using $2.5 \% \mathrm{NaOCl}$ and $17 \%$ EDTA solution then the canals were finally flushed with $5 \mathrm{ml}$ distilled water.

Teeth were then divided into six equal groups, four experimental and two control groups of ten teeth each. Obturation was performed according to the grouping.

In group I, ten roots were obturated by CPoint and Endosequence bioceramic sealer. The tip of the syringe was inserted into the canal no deeper than the coronal one third. Gently and smoothly a small amount (1-2 calibration markings) of the sealer was dispensed into the root canal by compressing the plunger of the syringe. The CPoint cone (size F4) was lightly coated with sealer then it was slowly inserted with a slight pumping motion to evenly distribute the sealer until it was fully seated. Obturation was done using Single-cone technique.

In group II, ten roots were obturated with Protaper gutta percha with Endosequence bioceramic sealer. The sealer was inserted into the root canal as the previous group, the master gutta percha cone (size F4) was coated with the sealer then it was inserted in the canal with a pumping motion until it was fully seated. The obturation was completed using conventional lateral condensation technique with accessory gutta percha cones.

In group III, ten roots were obturated with Protaper gutta percha with Adseal resin sealer. The base and catalyst were mixed on a mixing pad using spatula until reaching creamy homogeneous consistency, sealer carried to the canal using a \#15 hand file, rotated in an anti-clockwise direction, the master gutta percha cone (size F4) was coated with the sealer and then inserted with a pumping motion until it was fully seated. The obturation was completed using conventional lateral condensation technique with accessory gutta percha cones.

In group IV, ten roots were obturated by Protaper gutta percha Points and MTA Fillapex sealer. The selfmixing tip was attached to the syringe then the sealer was immediately placed after mixing, it was applied in the root canal directly using an applicator tip adapted to the self-mixing tip, the gutta-percha was coated with a thin layer of the sealer then inserted until it was fully seated. The obturation was completed using conventional lateral condensation technique with accessory gutta percha cones.

In group $\mathrm{V}$, ten roots were prepared but not obturated and kept opened to act as a positive control group.

In group VI, ten roots were filled with Protaper gutta percha and Adseal resin sealer using lateral condensation technique to act as a negative control group.

After obturation, all specimens were stored at $37^{\circ} \mathrm{C}$ at $100 \%$ humidity for two weeks to allow full setting of the sealer. Good quality radiographs had been taken to 
verify the quality of the root fillings. The external surfaces for groups (I, II, III, IV), except the coronal access and the apical $2 \mathrm{~mm}$, were covered with two layers of nail polish and sticky wax. For group V, the external surface was not covered with nail polish. For group VI, root surfaces were completely covered with two layers of nail polish including the apex of the root and coronal access.

A split-chamber model (15) was used for bacterial leakage evaluation using natural human saliva. Briefly, the tapered end of a 2-ml plastic eppendorf tube was cut and each root was placed into the tube. The root was positioned inside the tube so that its apical end was protruding from the cut-end section of the eppendorf tube. The junction between the plastic tube and the root was sealed with cyanoacrylate glue and nail polish. The apparatus (teeth and plastic tubes) were sterilized by exposure to Ultraviolet rays. Then the eppendorf tube containing the samples was placed in a glass bottle containing $3 \mathrm{ml}$ sterile Schaedler broth so that at least 2 $\mathrm{mm}$ of the root apex was immersed in the broth (as shown in figure 1).

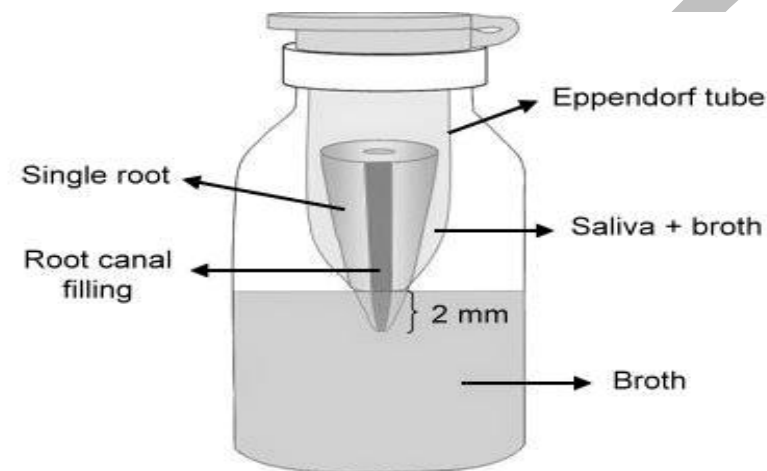

Fig. (1): Diagrammatic illustration of the apparatus used in this study.

The junction between the eppendorf and the glass bottle was sealed tightly with sticky wax and parafilm M. Each sample was enumerated for identification. To verify sterilization, the whole apparatus was incubated for 3 days at $37^{\circ} \mathrm{C}$ to check any turbidity in the broth of the lower chambers.

The coronal chambers were filled with $1 \mathrm{ml}$ of the mix of human saliva and broth (ratio 3:1). The saliva was collected from a single volunteer who did not brush for 12 hours before collection or were on antibiotic therapy. The system was stored in an anaerobic incubator with an anaerobic gas pack at $37^{\circ} \mathrm{C}$ and any changes in opacity of the broth in the apical chamber was checked daily for identification of bacterial contamination for up to 60 days (as shown in figure 2). If no turbidity was observed in the apical chamber for up to 7 days, the medium in the coronal chamber was changed.

Data was submitted to the non-parametric KaplanMeier statistical analysis to a 5\% significance level ( $\mathrm{p}<0.05)$, estimating the mean time of leakage in days for all groups. The results were statistically analyzed using
Kruskal Wallis and Monte Carlo test.

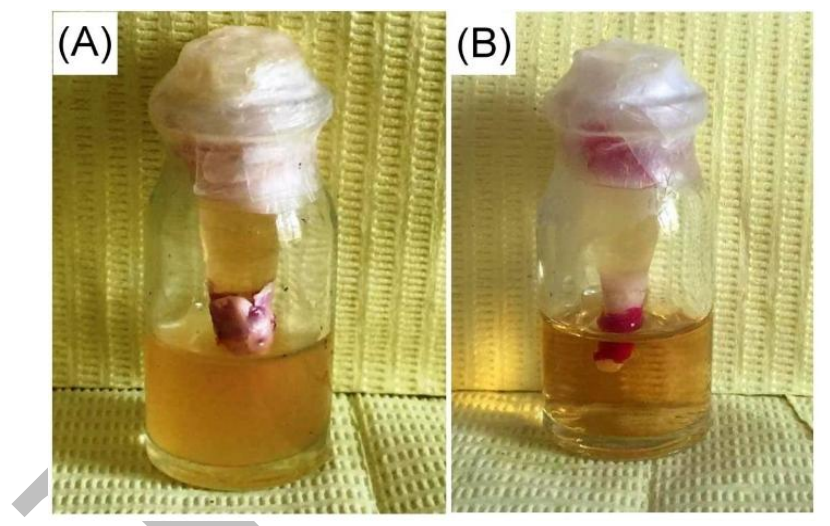

Fig. (2): a) Sample showing turbidity of the broth in the lower chamber; b) Sample showing clear broth in the lower chamber.

\section{RESULTS}

The daily contamination of obturated root canals of all groups after exposure to natural human saliva for a period of 60 days is shown in table 1 .

\begin{tabular}{|c|c|c|c|c|c|c|}
\hline Groups & $\begin{array}{c}\text { Group } \\
\text { (1) }\end{array}$ & $\begin{array}{l}\text { Grou } \\
\mathrm{p}(2)\end{array}$ & $\begin{array}{l}\text { Group } \\
\text { (3) }\end{array}$ & $\begin{array}{l}\text { Group } \\
\text { (4) }\end{array}$ & $\begin{array}{c}\text { Group } \\
(5)\end{array}$ & $\begin{array}{c}\text { Group } \\
\text { (6) }\end{array}$ \\
\hline $\begin{array}{l}\text { Sample } \\
\text { number }\end{array}$ & $\begin{array}{c}\text { Cpoint + } \\
\text { BC } \\
\text { sealer }\end{array}$ & $\begin{array}{c}\mathrm{GP}+ \\
\mathrm{BC} \\
\text { sealer }\end{array}$ & $\begin{array}{l}\text { GP + } \\
\text { Resin } \\
\text { sealer }\end{array}$ & $\begin{array}{l}\text { GP + } \\
\text { MTA } \\
\text { sealer }\end{array}$ & $\begin{array}{c}\text { Positive } \\
\text { control }\end{array}$ & $\begin{array}{c}\text { Negative } \\
\text { control }\end{array}$ \\
\hline 1 & 6 & 6 & 5 & 5 & 2 & --- \\
\hline 2 & 8 & 7 & 7 & 7 & 2 & --- \\
\hline 3 & 13 & 11 & 13 & 9 & 2 & --- \\
\hline 4 & 20 & 14 & 22 & 16 & 2 & --- \\
\hline 5 & 34 & 25 & 37 & 17 & 2 & --- \\
\hline 6 & 52 & 36 & 42 & 19 & 2 & --- \\
\hline 7 & --- & 42 & 43 & 19 & 2 & --- \\
\hline 8 & --- & --- & 49 & 21 & 2 & --- \\
\hline 9 & --- & --- & 53 & 24 & 2 & --- \\
\hline 10 & --- & --- & --- & 32 & 2 & --- \\
\hline
\end{tabular}

Table (1): The daily contamination of obturated root canals of all groups after exposure to natural human saliva for a period of 60 days.

All samples of the positive control group showed leakage on the second day, indicating the ability of saliva to penetrate the prepared root canals. Also, none of the negative control specimens leaked within 60 days, indicating that the seal created between the twochambers of the systems was efficient.

Regarding the days of contamination, all experimental groups showed leakage throughout the study period, Group I showed the best results with a mean of $(37.30 \pm 23.61)$ days while Group II and III showed nearly equal results with a mean of $(32.10 \pm$ $22.57)$ and (33.10 \pm 19.90$)$ days, respectively. Group IV showed the worst results with a mean of $(16.90 \pm 8.21)$ days and was found to be statistically significant than the other groups $(\mathrm{P}=0.048)$. (As shown in table 2 ) 


\begin{tabular}{|c|c|c|c|c|c|c|}
\hline & \multicolumn{4}{|c|}{ Sealer } & \multirow[b]{2}{*}{${ }_{2}^{\mathrm{KW}} \chi$} & \multirow[b]{2}{*}{$\mathrm{p}$} \\
\hline & $\begin{array}{c}\text { CPoint } \\
+\mathrm{BC} \\
(\mathrm{n}= \\
10)\end{array}$ & $\begin{array}{c}\mathrm{GP}+ \\
\mathrm{BC} \\
(\mathrm{n}= \\
10)\end{array}$ & $\begin{array}{c}\mathrm{GP}+ \\
\text { Resin } \\
(\mathrm{n}= \\
10)\end{array}$ & $\begin{array}{c}\text { GP+ } \\
\text { MTA } \\
(\mathrm{n}= \\
10)\end{array}$ & & \\
\hline Contamination & \multirow{2}{*}{$\begin{array}{l}6.0- \\
60.0\end{array}$} & \multirow{2}{*}{$\begin{array}{l}6.0- \\
60.0\end{array}$} & \multirow{2}{*}{$\begin{array}{l}5.0- \\
60.0\end{array}$} & \multirow{2}{*}{$\begin{array}{l}5.0- \\
32.0\end{array}$} & \multirow{4}{*}{10.3} & \multirow{4}{*}{0.048} \\
\hline $\begin{array}{l}\text { Min. - } \\
\text { Max. }\end{array}$ & & & & & & \\
\hline $\begin{array}{c}\text { Mean } \pm \\
\text { SD. }\end{array}$ & $\begin{array}{l}37.30 \\
\pm \\
23.61\end{array}$ & $\begin{array}{c}32.10 \\
\pm \\
22.57\end{array}$ & $\begin{array}{c}33.10 \\
\pm \\
19.90\end{array}$ & $\begin{array}{c}16.90 \\
\pm \\
8.21\end{array}$ & & \\
\hline Median & 43.0 & 30.50 & 39.50 & 18.0 & & \\
\hline $\begin{array}{l}\text { Post hoc } \\
\text { adjusted } \\
\text { analysis }\end{array}$ & \multicolumn{4}{|c|}{$\begin{array}{l}\text { Group IV is significantly different } \\
\text { from the others }\end{array}$} & & \\
\hline
\end{tabular}

Table (2): Comparison between the different studied groups according to the days of contamination of each obturated root canal after exposure to natural human saliva.

$$
\begin{aligned}
& { }^{\mathrm{KW}} \chi^{2} \text { : Chi square for Kruskal Wallis test } \\
& * \text { : Statistically significant at } \mathrm{p} \leq 0.05
\end{aligned}
$$

Regarding the percentage of samples that leaked at the end of the observational period, it was found that $60 \%$ of roots in group I showed leakage, while in group II $70 \%$ of roots showed leakage, $90 \%$ of roots showed leakage in group III and $100 \%$ of roots in group IV showed leakage. The observed differences were found to be statistically non-significant $(P=0.208)$ (As shown in

\begin{tabular}{|c|c|c|c|c|c|c|c|c|c|}
\hline & \multicolumn{2}{|c|}{$\begin{array}{c}\text { CPoint }+ \\
\text { BC } \\
(\mathrm{n}=10) \\
\end{array}$} & \multicolumn{2}{|c|}{$\begin{array}{c}\mathrm{GP}+\mathrm{BC} \\
(\mathrm{n}=10)\end{array}$} & \multicolumn{2}{|c|}{$\begin{array}{c}\text { GP + } \\
\text { Resin } \\
(n=10)\end{array}$} & \multicolumn{2}{|c|}{$\begin{array}{c}\mathrm{GP}+ \\
\mathrm{MTA} \\
(\mathrm{n}=10)\end{array}$} & \multirow[t]{2}{*}{${ }^{M C} \mathbf{p}$} \\
\hline & No. & $\%$ & No. & $\%$ & No. & $\%$ & No. & $\%$ & \\
\hline $\begin{array}{c}\text { Non - } \\
\text { Contaminated }\end{array}$ & 4 & 40 & 3 & 30 & 1 & 10 & 0 & 0 & 0208 \\
\hline Contaminated & 6 & 60 & 7 & 70 & 9 & 90 & 10 & 10 & \\
\hline
\end{tabular}
table 3).

Table (3): Comparison between the different studied groups according to the $\%$ of contaminated and non-contaminated samples after exposure to natural human saliva for 60 days.

MC: Monte Carlo test *: Statistically sig. at $\mathrm{p} \leq 0.05$

\section{DISCUSSION}

All stages of endodontic therapy have equal importance, although more emphasis is given to obturation as its quality can determine the success or failure of therapy (16).

Ingle and backland stated that $60 \%$ of failures in endodontics can be attributed to incomplete obturation of the root canals (17). This demands three-dimensional obturation to decrease the microleakage that may occur through the root canal filling.
Microleakage is one of the most crucial causes of endodontic failure and is defined as the passage of bacteria, fluids, and chemical substances between the root structure and filling material (18). Microleakage in endodontics is multi-factorial, as it may depends on several factors as root filling technique, root filling material, type of sealer used and bonding to root canal walls. So sealing all the communication pathways between the coronal and apical portions of the root canal system is necessary for the long-term success of the root canal therapy.

In this study we examined the hypothesis that: the newly self-expanding hydrophilic CPoint obturation system and BC sealer would be able to prevent or decrease bacterial microleakage when compared to gutta percha with different type of sealers.

Mandibular premolars with single canals were selected for this study as they have oval shaped canals, providing space between the rounded gutta percha and the root canal walls, such space will need greater amount of sealer between the filling material and root canal walls, which requires the use of a sealer with optimum sealing ability.

Formalin solution was not used for storage of teeth as it has strong bactericidal effect (19) which might affect the bacterial leakage through the obturation material and it also might affect the bonding to dentin since it promotes cross-linking of collagenous proteins present in the dentin matrix leading to an accumulation of insoluble products along the canal wall after instrumentation which might influence sealer penetration resulting in the alteration of the seal (20).

For standardization, the teeth were decoronated and the length of all roots were fixed to $12 \mathrm{~mm}$, as it was found by Metzger et al (21) and Mozini et al (22) that the length of the filling material would affect the speed rate of bacterial leakage. Also the volume of the canals was standardized to the same taper and size by the use of universal ProTaper rotary files in a Crown down technique till size F4.

During instrumentation, a smear layer is formed covering the dentin surface of the prepared root canals. This layer consists of organic and inorganic substances which includes microorganisms and necrotic tissues, occluding the dentinal tubules. This will prevent penetration of sealers and the complete adaptation of the obturating material to the prepared root surfaces which might increase leakage. Grandini et al (23) and Lim et al (24) recommended the removal of both organic and inorganic components of the smear layer using a combined application of Glyde file prep and $2.5 \% \mathrm{NaOCl}$, in accordance to the present study. Glyde file prep was used due to the adjunctive effect of EDTA on the smear layer and the effervescence which occurs due to the reaction between carbamide peroxide and sodium hypochlorite allowing dentinal shavings and pulpal remnants to be readily removed (25). It was also found by Baumgartner et al (26) that the removal of the smear 
layer from the instrumented canal would leave a smoothly planed surface with patent tubular orifices that range from 2 to $4 \mu \mathrm{m}$ in diameter.

$17 \%$ EDTA solution was used for $1 \mathrm{~min}$ only, as increasing the time of exposure makes dentin susceptible to erosion (27). $\mathrm{NaOCl}$ was not used as a last irrigant as it is a strong oxidizing agent leaving behind an oxygenrich layer on the dentine surface, which results in a reduced bond strengths to sealers. So distilled water was used as a final flush in order to minimize the compromising effect of $\mathrm{NaOCl}$ (28).

For standardization of obturation technique, lateral condensation technique was used in all groups except the CPoint group, which was used as a single cone. The main advantage of the CPoint system, according to the manufacturer, is its lateral expansion which occurs until it becomes prestressed by the contact with the canal walls. This exclusive property may be lost if it was used in conjugation with the lateral condensation technique.

Several methods have been described to evaluate the sealing quality of obturated root canals. Although each technique has its proponents, there is no general consensus in the profession as to which technique is the best (29). The model used in this study was the splitchamber bacterial leakage model which was firstly designed by Torabinejad et al (1990) (13). It has been modified and used by several other researchers for coronal leakage studies $(12,30)$. This model was used as it is more clinically relevant, producing more precise and reproducible data (13), using the etiologic agent of apical periodontitis (14).

The results of the negative control group in this study were $0 \%$ as none of the ten teeth used showed any leakage. Their broth remained clear all through the study period. This proved that the seal between the two chambers of the system was efficient.

Group I (CPoint + BC sealer) showed the best coronal seal by reducing the speed of bacterial leakage. These findings may be attributed to the expansion property possessed by the CPoint cones, where the cones were designed to expand laterally without expanding axially by absorbing residual water from the instrumented root canal space and the naturally present moisture in the dentinal tubules. This post-setting expansion shows an approximately $14 \%$ expansion after 20 minutes (10) which could provide better sealing and adhesive properties, as it decreases the gaps and voids found between the main cone and the root canal walls. Also the use of bioceramic sealer with CPoint cones provided better sealing ability due to the slow setting time of bioceramic sealer which provides more time for the expansion of the CPoints pushing the sealer towards dentinal walls so better filling of the canals irregularities. Also it has been shown that the release of calcium and hydroxyl ions from the calcium silicate-containing material results in the formation of an apatite layer. Formation of this interfacial layer develops a chemical bond between calcium silicate-based materials and dentinal walls decreasing the marginal leakage and gaps (3). Moreover, BC Sealer's extremely small particle size (2 $\mu \mathrm{m})(31)$ and hydrophilic nature allow it to flow into all aspects of the canal anatomy. The present results confirmed the findings reported by Hegde and Arora (15, 32) that CPoint cones with BC sealer showed better sealing ability than laterally condensed gutta percha with resin sealer. Furthermore, El-Sayed et al (33) showed that the novel hydrophilic Smart-Seal system provided better sealing ability when compared to other single-cone obturation systems.

According to group II (GP + BC sealer) and group III (GP + Resin sealer), both groups showed nearly equal results in delaying coronal bacterial leakage. Both types of sealers form chemical bond to dentinal walls which might provide better sealing ability which in turn should reduce leakage in clinical situations. Bonding of resin sealer may be associated with its ability to react with any exposed amino groups in collagen to form covalent bonds between the resin and collagen upon opening of the epoxide ring $(34,35)$. The results of this study coincide with that of Zhang et al (36) who found that there was no statistically significant difference between $\mathrm{BC}$ and Resin sealer in sealing ability when EDTA was used as irrigant. On the other hand, Al-Zaka et al (37) found that resin sealer provided better sealing ability than bioceramic sealer when EDTA used as an irrigant. It may be attributed to the effect of EDTA as it alters the surface energy of dentin which significantly decrease the wetting ability of dentin (37) thereby providing a suitable dentin substrate for adhesion of materials of a hydrophobic nature like Resin sealers. On the contrary, it would affect the adhesion of hydrophilic materials like BC sealer.

Group IV (GP + MTA sealer) showed the worst results, where all samples showed leakage within 32 days. This results are in line with Sonmez et al (5) who found that MTA Fillapex sealer showed inferior sealing ability when compared with resin sealer and MTA, they attributed that to salicylate resin component of the MTA Fillapex, which might adversely affect its sealing properties (38). Also Borges et al (39) used scanning electron microscopy to show that porosities and cracks occurred in the resin matrix of MTA Fillapex after subjecting to solubility test by immersion in water after setting, which might affect its molecular stability. On contrary, Ferreira et al (40) stated that MTA-based sealers showed reduction in leakage values over time, which could be attributed to the volumetric expansion after setting.

It was difficult to directly compare results of this study with those of other investigators as many different factors in the spectrum of the model systems used could account for variability of penetration data reported. These include type of teeth, amount of remaining tooth structure, preparation technique, obturation materials, model design, selection of organisms, sterilization techniques, and sample size. 


\section{CONCLUSIONS}

It was concluded from this study that:

1) None of the tested materials were able to provide a complete hermetic seal, where all groups showed leakage within the study period.

2) CPoint with endosequence bioceramic sealer provided the best coronal seal by reducing the speed of bacterial penetration through the root canal filling. MTA Fillapex had an inferior coronal seal compared to the other groups.

3) Single-cone obturation with well-fitted CPoint cones and bioceramic sealer is an alternative for traditional lateral compaction technique.

\section{ACKNOWLEDGEMENT}

I would like to thank Nayrouz Adel and Moustafa Fathy for their continuous support during conduction of this study.

\section{CONFLICT OF INTEREST}

The authors declare that they have no conflicts of interest.

\section{REFERENCES}

1. Schäfer E, Olthoff G. Effect of Three Different Sealers on the Sealing Ability of Both Thermafil Obturators and Cold Laterally Compacted Gutta-Percha. J Endod. 2002;9:638-42.

2. Hess D, Solomon E, Spears R, He J. Retreatability of a Bioceramic Root Canal Sealing Material. J Endod. 2011;11:1547-9.

3. Shokouhinejad N, Gorjestani H, Nasseh A, Hoseini A, Mohammadi M, Shamshiri A. Push-out bond strength of gutta-percha with a new bioceramic sealer in the presence or absence of smear layer. Aust Endod J. 2011;3:1-6.

4. Torabinejad M, Parirokh M. Mineral Trioxide Aggregate: A Comprehensive Literature Review-Part II: Leakage and Biocompatibility Investigations. J Endod. 2010;2:190-202.

5. Sonmez I, Oba A, Sonmez D, Almaz M. In vitro evaluation of apical microleakage of a new MTA-based sealer. Eur Arch Paediatr Dent. 2012;5:252-5.

6. Mokhtari H, Shahi S, Janani M, Reyhani M, Mokhtari Z, Rahimi S et al. Evaluation of apical leakage in root canals obturated with three different sealers in presence or absence of smear layer. Iran Endod J. 2015;2:131-4.

7. Marina A, Bruno M, Ordinola-Zapata R, Clovis M, Bruno C, Roberto B et al. Physical Properties and Interfacial Adaptation of Three Epoxy Resin-based Sealers. J Endod. 2011;10:1417-21.

8. Krishnan Hari. Water-Expandable Endodontic Obturation Point: A Review. RRJDS 2014;1:37-41.

9. Arora S, Hegde V. Comparative evaluation of a novel smart-seal obturating system and its homogeneity of using cone beam computed tomography: In vitro simulated lateral canal study. J Conserv Dent.
2014;4:364-8.

10. Didato A, Eid A, Levin M, Khan S, Tay F, Rueggeberg F. Time-based lateral hygroscopic expansion of a waterexpandable endodontic obturation point. $\mathbf{J}$ Dent. 2013;9:796-801.

11. Aminsobhani M, Ghorbanzadeh A, Bolhari B, Shokouhinejad N, Ghabraei S, Assadian H et al. Coronal microleakage in root canals obturated with lateral compaction, warm vertical compaction and guttaflow system. Iran Endod J. 2010;2:83-7.

12. Eldeniz A, Orstavik D. A laboratory assessment of coronal bacterial leakage in root canals filled with new and conventional sealers. Int Endod J. 2009;4:303-12.

13. Torabinejad M, Ung B, Kettering J D. In vitro bacterial penetration of coronally unsealed endodontically treated teeth. J Endod. 1990;12:566-9.

14. Barthell CR, Moshonov J, Shuping G, Orstavik D. Bacterial leakage versus dye leakage in obturated root canals. Int Endod J. 1999;32:370-5.

15. Hegde V, Arora S. Sealing ability of a novel hydrophilic vs. conventional hydrophobic obturation systems: A bacterial leakage study. J Conserv Dent. 2015;1:62-5.

16. Silva G, Silva E, Silva J, Andrade-Junior C, Ferraz C. Sealing ability promoted by three different endodontic sealers. Iran Endod J. 2011;2:86-9.

17. Ingle JI, Bakland LK. Endodontics. 5th ed. London: BC Decker Inc; 2002.

18. Mitic A, Mitic N, Tosic G. Apical leakage of root canal system obturation materials. Serb Dent J. 2005;52:90-6.

19. Gerald M, Denver R. Antiseptics and Disinfectants: Activity, Action, and Resistance. Clin Microbiol Rev. 1999;1:147-79.

20. George S, Pichardo M, Bergeron B, Jeansonne B. The effect of formalin storage on the apical microleakage of obturated canals. J Endod. 2006;9:869-71.

21. Metzger Z, Abramovitz R, Abramovitz L, Tagger M. Correlation between remaining length of root canal fillings after immediate post space preparation and coronal leakage. J Endod. 2000;12:724-8.

22. Mozini A, Vansan P, Neto M, Pietro R. influence of the length of remaining root canal filling and post space preparation on the coronal leakage of Enterococcus Faecalis. Braz J Microbial. 2009;40:174-9.

23. Grandini S, Balleri P, Ferrari M. Evaluation of Glyde File Prep in Combination with Sodium Hypochlorite as a Root Canal Irrigant. J Endod. 2002;4:300-3.

24. Lim TS, Wee TY, Choi MY, Koh WC, Sae-Lim V. Light and scanning electron microscopic evaluation of Glyde $^{\mathrm{TM}}$ File Prep in smear layer removal. Int Endod J. 2003;5:336-43.

25. Kanodia S, Matta S, Parmar J. Stereomicroscopic and scanning electron microscopic evaluation of glyde file prep in smear layer removal. IJHBR. 2014;2:170-7.

26. Baumgartner JC, Mader CL. A scanning electron microscopic evaluation of four root canal irrigation regimens. J Endod. 1987;13:147-57.

27. Semra C, Ahmet S. Time-Dependent Effects of EDTA on Dentin Structures. J Endod. 2002;1:17-9. 
28. Lai SC, Mak YF, Cheung GS. Reversal of compromised bonding to oxidized etched dentin. J Dent Res. 2001;80:1919-24.

29. Malik G, Bogra P, Singh S, Samra R. Comparative evaluation of intracanal sealing ability of mineral trioxide aggregate and glass ionomer cement: An in vitro study. J Conserv Dent. 2013;6:540-45.

30. Shipper G, Orstavik D, Teixeira F, Trope M. An evaluation of microbial leakage in roots filled with a thermoplastic synthetic polymer-based root canal filling material (Resilon). J Endod. 2004;5:342-7.

31. Pratishta J, Manish R. The rise of biocramics in endodontics : A review. Int J Pharm Bio Sci. 2015:41622.

32. Hegde V, Arora S. Sealing ability of three hydrophilic single-cone obturation systems: An in vitro glucose leakage study. Contemp Clin Dent. 2015;1:86-9.

33. El-Sayed MA, Taleb AA, Balbahaith MM. An in vitro comparative analysis of glucose leakage for three contemporary single-cone obturation systems. J Res Dent. 2014;1:1-5.

34. Ersahan S, Aydin C. Dislocation resistance of iRoot SP, a calcium silicate-based sealer, from radicular dentine. $\mathrm{J}$ Endod. 2010;12:2000-2.

35. Lee W, Williams M, Camps J, Pashley D. Adhesion of Endodontic Sealers to Dentin and Gutta-Percha. J Endod. 2002;10:684-8.

36. Zhang W, Li Z, Peng B. Assessment of a new root canal sealer's apical sealing ability. Oral Surg Oral Med Oral Pathol Oral Radiol Endod. 2009;6:79-82.

37. Al-Zaka I, Ammar A, Hikmet A, Mehdi J. The effect of different root canal irrigants on the sealing ability of Bioceramic sealer. MDJ. 2013;1:1-7.

38. Assmann E, Scarparo R, Böttcher D, Grecca F. Dentin bond strength of two mineral trioxide aggregate-based and one epoxy resin-based sealers. $\mathbf{J}$ Endod. 2012;2:219-21.

39. Borges RP, Sousa-Neto MD, Versiani MA, Rached-Júnior FA, De-Deus G, Miranda $\mathrm{C}$ et al. Changes in the surface of four calcium silicate-containing endodontic materials and an epoxy resin-based sealer after a solubility test. Int Endod J. 2012;5:419-28.

40. Ferreira MM, Abrantes M, Ferreira H, Carrilho E, Botelho M. Comparison of the apical seal on filled root canals with Topseal vs MTA Fillapex sealers: A quantitative scintigraphic analysis. OPST. 2013;3:12832. 